\title{
Os corvos de Púchkin: a tradução da tradução
}

Ekaterina Vólkova Américo

\begin{abstract}
Resumo
A história das traduções de Aleksandr Púchkin no Brasil, bem como a dos estudos puchkinianos, evidencia lacunas existentes nessas áreas, principalmente no que diz respeito a sua herança poética. Em seguida, dedico-me ao caso particular do poema de Púchkin Os corvos (1828), uma tradução livre das baladas escocesas The three ravens $e$ The twa Corbies, publicadas por Walter Scott em 1802-1803. A análise semântica do poema demonstra transformações significativas em relação às baladas originais. Por sua vez, a consciência sobre a origem folclórica do poema puchkiniano predestinou muitas das escolhas feitas por tradutores brasileiros, Boris Schnaiderman e Nelson Ascher.
\end{abstract}

Palavras-chave: Aleksandr Púchkin; Poesia Russa; Tradução; Semiótica da Cultura. 


\section{Um Púchkin brasileiro}

Considerado pelos russos o fundador da literatura e, principalmente, da poesia russa, Aleksandr Púchkin, não ganhou tamanha fama fora do seu país, ofuscado pelos grandes romancistas, principalmente por Dostoiévski e Tolstói. A mesma preferência pode ser observada também no Brasil. Em grande parte, essa disparidade se deve à influência da cultura francesa e, em especial, do livro O romance russo (1886) de Eugène-Melchior de Vogüé que predestinou em muito os caminhos da recepção da literatura russa no Ocidente (GOMIDE, 2004, p. 14-15). Outra declaração de Vogüé que teve grande impacto no processo de divulgação da obra de Púchkin no exterior se refere ao mito sobre a impossibilidade de transpor a poesia russa para outras línguas:

Os poetas russos não são e não serão jamais traduzidos. Um poema lírico é um ser vivo, de uma vida furtiva, que reside no arranjo das palavras; não se transporta essa vida para um corpo estranho (VOGUE, 1950, p. 18).

Ainda que essas palavras tanjam à poesia russa como um todo, Vogüé as estende também à obra de Púchkin, citando-as, inclusive, atribui ao próprio poeta que parecia pressentir as dificuldades relacionadas à tradução da sua obra, principalmente poética:

Pelos motivos indicados não entrarei aqui nos detalhes da sua obra. Seria preciso citar, traduzir essa língua de diamante; é uma empreitada para enlouquecer-nos de desespero. Ele próprio [Púchkin] afirmava: “Na minha opinião, nada mais difícil do que traduzir versos russos em versos franceses; dada a concisão da língua não se pode jamais ser suficientemente breve". Mérimée observou com muita justeza que somente o latim poderia exprimir tantos pensamentos em tão poucas palavras, com o mesmo brilho, os mesmos contornos. [...]. Assim morreria essa poesia, se eu a transportasse para estas páginas (VOGUE, 1950, p. 76-77).

Dessa forma, Vogüé relaciona os empecilhos tradutórios à concisão da língua russa e nem entra em questões de transposição métrico-rítmica. Em seguida, ele declara que o "gênio particular" da literatura russa deve ser procurado em prosa e não em poesia. Para o crítico francês, o realismo dos escritos de Turguênev, Tolstói e Dostoiévski encontrava-se à frente da herança literária de Púchkin e esse ser posicionamento 
explica em grande parte a trajetória da tradução da obra puchkiniana no Brasil.

Inicialmente, os seus textos eram majoritariamente lidos em francês, às vezes, também em inglês e alemão, fato confirmado pela grafia diversificada do seu nome: ora como Pushkin, ora como Pouchkine ou Puchkine, como no trecho de Vogüé citado acima (GOMIDE, 2004, p. 22). A propósito, Prosper Mérimée, também mencionado por Vogüé, foi um dos primeiros tradutores do poeta russo para o francês e vice-versa.

Em comparação com as traduções de Dostoiévski e Tolstói, as de Púchkin tardaram a aparecer e se restringiram inicialmente à prosa. Segundo os dados levantados por Denise Bottmann (2014, p. 241), Púchkin estreou no Brasil apenas em 1933 (ou seja, quase cem anos após a sua morte) com a novela A filha do capitão traduzida, ao que tudo indica, do francês. Em 1935, foi publicado o segundo livro sob um misterioso título de Águia negra. Trata-se, na verdade, da novela inacabada Dubróvski, cujo título foi alterado por questões mercadológicas: afinal, quem compraria um livro de um autor desconhecido com um título estranho e pouco informativo?

Boris Schnaiderman também publicou essa obra sob "semipseudônimo" de Boris Solomonov pouco tempo depois, em 1949. No ensaio A aventura dos títulos, o tradutor conta que também foi obrigado pela editora a adotar o título A águia negra e explica que tal escolha foi motivada pela referência ao filme norte-americano The eagle, de 1925, acrescentando ainda que o título "não tem nada a ver com o texto" (SCHNAIDERMAN, 2015, p. 36).

Não vou listar aqui todas as publicações na ordem cronológica, pois o levantamento minucioso das "aventuras" de Púchkin no Brasil já foi realizado por Denise Bottmann (2012). Nos anos 1960, começam a surgir as primeiras traduções diretas assinadas por Boris Schnaiderman, que depois integraram a coletânea $A$ dama de espadas. Prosa e Poemas (PÚCHKIN, 2013). Já nas duas últimas décadas do século passado ocorre um salto qualitativo e uma intensificação das traduções de Púchkin, especialmente diretas: além das traduções de Boris Schnaiderman, são publicados os trabalhos de Helena Nazário, Tatiana Belinky, Klara Gouriánova, Irineu Franco Perpétuo, Oleg Almeida e Cecília Rosas, entre outros (BOTMANN, 2014, p. 246-247). 
Resumindo a trajetória puchkiniana no Brasil, é possível dizer que, no momento, grande parte da sua obra prosaica já foi vertida para o português, sendo que a maioria das traduções foi feita nos últimos anos e diretamente do russo. No caso de algumas obras, existe mais de uma tradução direta: por exemplo, as versões dos Contos de Biélkin assinadas por Klara Gourianova (PUSHKIN, 2003), Cecília Rosas (PÚCHKIN, 2010) e Boris Schnaiderman (PÚCHKIN, 2013). Nota-se também o número crescente de trabalhos críticos sobre a sua obra, como por exemplo, os ensaios e comentários de Boris Schnaiderman, dossiê Púchkin do Caderno da Literatura e Cultura Russa (2004), bem como dissertações, teses, artigos e livros.

No que diz respeito à poesia, as primeiras traduções diretas são de autoria de José Casado (1992). Pouco depois, em 1999, a parceria entre Boris Schnaiderman e Nelson Ascher resultou no já citado livro $A$ dama de espadas que reuniu, além de prosa, alguns dos seus poemas mais famosos e, entre eles, Os corvos, objeto da minha análise a seguir.

De modo geral, apesar da efervescência das traduções da literatura russa que se deu nas últimas décadas e do admirável trabalho de Boris Schnaiderman em parceria com os irmãos Campos e Nelson Ascher, de Aurora Bernardini e outros autores, a tradução da poesia russa ainda permanece um campo emergente, um desafio e o mesmo pode ser dito a respeito dos trabalhos críticos sobre a poesia e o processo de sua tradução.

\section{Sobre corvos, heróis e cavaleiros}

A questão da tradução não diz respeito apenas à recepção da herança literária de Púchkin no exterior, mas integra a sua própria obra, pois Púchkin foi também atuou como tradutor. Em muitos casos, tratava-se de versões que hoje chamaríamos de bastante livres e indiretas (algo muito comum à época). Por exemplo, ele verteu para o russo o poema de Tomás António Gonzaga, mais precisamente com a sua lira IX, parte II da Marília de Dirceu (SCHNAIDERMAN, 2004). No século XX, com o surgimento dos estudos puchkinianos, surgiu uma discussão sobre a língua a partir da qual o poeta russo teria traduzido a lira, pois ele mesmo denominou a sua obra como "tradução do 
português" e se referiu ao autor como "Gonzago". No entanto, ao comparar a lira original, a tradução francesa e o texto de Púchkin, Schnaiderman conclui que nesse caso também tratase de uma tradução indireta, feita a partir do francês. Algo semelhante pode ser observado em relação a Os corvos.

O poema de Púchkin, datado de 1828 , foi publicado pela primeira vez um ano depois no almanaque literário Siévernyie tsvetý (As flores do norte), com subtítulo Canção Escocesa que dá algumas pistas sobre a sua origem. Segundo Borís Tomachévski (1977, p. 441), trata-se de uma tradução livre de uma das baladas escocesas reunidas Walter Scott na coletânea The Minestrelsy of the Scottish Border (1802-1803). Apesar de não especificar do qual balada se trata, Tomachévski afirma que a versão de Púchkin não se baseou na publicação original de Scott, mas na tradução francesa de 1826. A maioria dos puchkinistas concorda que a balada escocesa que inspirou Os corvos é The Twa corbies. Boris Schnaiderman e Nelson Ascher, os tradutores brasileiros do poema de Púchkin, compartilham da mesma opinião e, inclusive, adicionaram a tradução da balada, feita por Nelson Ascher, na parte dos comentários (PÚCHKIN, 2013, p. 256). Temos, portanto, o seguinte processo:

\section{The twa corbies $\longrightarrow$ Os corvos}

Como mostrarei adiante, a pesquisa sobre as origens do poema, realizada pelos tradutores, bem como a tradução da balada original, predestinou muitas das escolhas na sua interpretação do poema de Púchkin.

No entanto, Púchkin podia ter se baseado também na outra versão da balada, The three ravens (Os três corvos) publicada por Scott juntamente com The twa corbies e presente na nota explicativa da edição francesa de 1826. Nesse caso, o processo da criação do poema puchkiniano seria assim:

The twa corbies

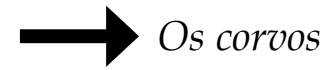

The three ravens

Apesar de certas semelhanças no nível de enredo - a conversa dos corvos precede a imagem do cavaleiro 
assassinado - as diferenças entre as duas versões também são notáveis. Além da divergência na quantidade dos corvos, a balada dos dois corvos é uma história de traição, enquanto na versão sobre três corvos trata-se de um amor fiel. Como veremos adiante, o texto de Púchkin oferece possiblidade dessa dupla leitura - tanto do amor fiel, quanto infiel - realizando, dessa forma, uma espécie de fusão semântica entre ambas as baladas. Portanto, a questão da origem do enredo puchkiniano revela-se de extrema importância.

Vários autores das teorias modernas sobre a tradução (por exemplo, AGAMBEN, 2007; ARROJO, 2007; LOTMAN, 2001) atentam para a necessidade de transferir a atenção da avaliação do resultado final (tradução fiel/infiel; tradução boa/ruim) para o processo que é concebido como essencialmente criativo. Assim, Rosemary Arrojo considera tradução um palimpsesto produtor de novos sentidos (2007, p. 23-24). Portanto, no que diz respeito às baladas, o poema de Púchkin e a sua tradução, a minha proposta é abordá-los como um todo, como um conjunto, embora heterogêneo, que pode ser representado da seguinte forma:

The twa corbies

$\rightarrow$ Os corvos de Púchkin $\rightarrow \begin{aligned} & \text { Os corvos (tradução de } \\ & \text { Schnaiderman-Ascher) }\end{aligned}$

The three ravens 
Apresento abaixo o poema acompanhado da sua tradução, realizada a quatro mãos por Boris Schnaiderman e Nelson Ascher:

\begin{tabular}{|c|c|}
\hline Ворон к ворону летит, & Corvo junto a corvo pousa, \\
\hline Ворон ворону кричит: & Corvo e corvo puxam a prosa: \\
\hline «Ворон, где б нам отобедать? & "Onde encontraremos nosso \\
\hline Как бы нам о том проведать?» & Alimento para almoço?" \\
\hline Ворон ворону в ответ: & Corvo a corvo então responde: \\
\hline «Знаю, будет нам обед; & "Ei-lo, corvo, já sei onde - \\
\hline В чистом поле под ракитой & Lá debaixo do salgueiro, \\
\hline Богатырь лежит убитый. & Jaz no prado um cavaleiro. \\
\hline Кем убит и отчего, & Quanto a quem, por que razão, \\
\hline Знает сокол лишь его, & O matou, só seu falcão, \\
\hline Да кобылка вороная, & Seu corcel e noiva tem \\
\hline Да хозяйка молодая». & Isso claro - mais ninguém". \\
\hline Сокол в рощу улетел, & O falcão sumiu no céu. \\
\hline На кобылку недруг сел, & Quem fez mal monta o corcel. \\
\hline А хозяйка ждет мило́го, & E eis que a noiva aguarda o noivo, \\
\hline Не убитого, живого. & Não o morto, mas o novo. \\
\hline
\end{tabular}

A referência às origens folclóricas transparece já no nível métrico-rítmico. Embora o pé métrico das baladas publicadas por Scott seja o jambo, que também era o preferido de Púchkin, na tradução, o poeta russo optou por troqueu. Essa mudança de forma alguma é ocasional, pois na cultura russa e da Europa Ocidental o jambo associa-se ao estilo livresco, enquanto troqueu, com ênfase na primeira sílaba, costuma ser relacionado à canção popular, tanto lírica, quanto épica (GASPÁROV, 1990). Dessa forma, a escolha do troqueu aproxima o poema puchkinino à canção popular e, portanto, à balada. Na tradução brasileira, a arquitetônica métrico-rítmica do poema também remete o leitor a uma canção popular.

Os dois primeiros versos do poema trazem uma anáfora composta pela palavra "corvo", ausente nas baladas escocesas. A repetição dessa palavra onomatopeica na versão em português 
alude, no nível do "estrato fônico-linguístico" (INGARDEN, 1965), o crocito nefasto dos corvos. Desse modo, no texto de Schnaiderman-Ascher ouvimos ao mesmo tempo o crocito dos corvos e a sua conversa "traduzida" para a linguagem humana. Já no texto em russo, a anáfora da palavra vóron não se refere ao som emitido pelos corvos e sim a sua cor (vornói, preto). Portanto, em russo, o efeito fônico produzido pela repetição é menos perceptível e a ênfase é transferida para o nível semântico. Por que Púchkin precisou realçar a presença dos corvos em seu texto?

A relação entre o corvo e a morte é um lugar comum no folclore europeu e, por conseguinte, na literatura de diversos países e, é claro, seria impossível não lembrar aqui do bestseller de Poe (1845). A simbologia mitológica do corvo foi examinada a fundo na obra do semioticista Eleazar Meletínski. Referindo-se à hipótese levantada por Lévi-Strauss, Meletínski afirma que o fato de corvo se alimentar de carniça também o transforma em um mediador entre a vida e a morte (1980, p. 245), um herói cultural que, na mitologia de diversos povos, atua como um demiurgo. Ao mesmo tempo, o corvo é dotado de caraterísticas traiçoeiras de um trickster:

Como um pássaro cadavérico preto com um grito sinistro, o Corvo é ctônico, demoníaco e relacionado ao reino dos mortos e à morte, ao embate sangrento (o motivo de bicar os olhos da vítima recebe uma atenção especial), apresentandose como o mensageiro do mal (MELETÍNSKI, 1980, p. 245; tradução nossa).

A aparição dos corvos no primeiro verso do poema, portanto, não só prenuncia a morte, como também alude ao embate que a precedeu. Todos esses códigos, presentes nas baladas originárias, persistem no poema de Púchkin, inclusive, o motivo do corvo como mensageiro do mal e da batalha sangrenta. Além disso, a cena do crime é vista justamente pelos olhos do corvo, dotado de um omnisciência divina: ele não apenas sabe o que aconteceu "debaixo do salgueiro", como também aquilo que ocorre ao longe, na casa do cavaleiro assassinado.

Aliás, o salgueiro não aparece nas baladas: nelas, encontramos, respectivamente, o "velho açude" (PÚCHKIN, 2013, p. 256) e o "campo verde" (SCOTT, 1802-1803). No texto puchkiniano, a árvore é rakíta, espécie de salgueiro comumente 
1 Uma das minhas r e p r e s e $\mathrm{n} t$ a ç õ e s preferidas de bogatyr é o quadro homônimo de Mikhail Vrúbel de 1898. citado nos contos populares russos, ou nos "contos de magia", de acordo com a definição de Propp. Essa árvore é um divisor entre o mundo dos vivos e dos mortos e é embaixo dela que o personagem dos contos populares enfrenta os seus inimigos.

Além de prenunciar a tragédia, o salgueiro remete à imagem de arbor mundi que, segundo o semioticista Vladímir Toporov, é refletida em diversas manifestações da cultura humana, por exemplo, na poesia, arte, arquitetura e nos ritos (1980, p. 405). Fundamental para a organização do espaço mitológico, a árvore correlaciona as três dimensões: os céus (a sua copa se situa no plano divino), a vida (o tronco equivale ao plano terrestre) e a morte (as raízes se situam no plano subterrâneo). Além disso, os três planos podem ser interpretados como o futuro, o presente e o passado (TOPOROV, 1980, p. 398-399) e, dessa forma, no poema puchkiniano, o cavaleiro assassinado está relacionado simultaneamente ao mundo dos vivos e ao dos mortos e também se encontra em uma encruzilhada temporal, entre o passado e o futuro.

O motivo da batalha ainda remete ao ritual de sacrifício (que acompanha as narrativas sobre a árvore do mundo), necessário para garantir a fertilidade e a riqueza (TOPOROV, 1980, p. 401) e reflete o embate arquetípico entre o caos e o cosmos, como resultado do qual nasce um novo mundo, uma nova ordem (TOPOROV, 1980, p. 405). No plano do poema puchkiniano ocorre o mesmo: após a batalha, o lugar do cavaleiro é tomado por um outro, ou seja, estabelece-se uma nova ordem.

Quanto ao protagonista em si, o cavaleiro que nas baladas aparece como knight, no poema de Púchkin aparece como bogatyr, palavra relacionada ao universo do folclore russo. Os bogatyr eram heróis das canções épico-heroicas russas (bylina), dotados de uma força descomunal, que enfrentavam e venciam feras mitológicas e inimigos das terras eslavas. ${ }^{1}$ Naturalmente, Púchkin, ao transferir a narrativa folclórica escocesa à Rússia, buscou correspondências no folclore do seu país. Essa referência não foi mantida na tradução, mas, caso os tradutores optassem por estrangeirizar o poema inserindo no texto em português a palavra bogatyr, seria necessária uma nota explicativa que certamente deixaria o texto menos fluído. Por outro lado, a tradução de bogatyr como cavaleiro o devolve ao universo do folclore europeu e o aproxima do knight. 
A inserção do bogatyr no poema possui dois desdobramentos importantes. Em primeiro lugar, em todas as narrativas populares o bogatyr necessariamente derrota os seus inimigos, enquanto na obra puchkiniana ocorre algo oposto, impensável e impossível: o invencível herói é derrotado. Ao contrário das narrativas populares em que a morte do bogatyr é até possível, mas é sempre seguida de ressureição, o poema não deixa esperanças. A morte não é mitológica, mas real e irreversível. Até os seus companheiros fiéis, o falcão e o corcel, que na narrativa folclórica deveriam ajudar o herói a vencer ou ressuscitar (PROPP, 1984, p. 44), o abandonam. A derrota do bogatyr transfere o texto do universo folclórico para o literário. Dessa forma, na obra puchkiniana, os personagens e os enredos tipicamente folclóricos sofrem alterações significativas.

Apesar das diferenças semânticas entre o cavaleiro e o bogatyr, há algo que os une: ambos estão acompanhados por um cavalo. Ausente nas baladas, o cavalo é mais um traço adicionado por Púchkin. Na tradução brasileira, ele aparece como "corcel" e o corcel seria de fato um companheiro digno, à altura não só do cavaleiro, como também do herói-bogatyr. Assim, Roman Jakobson observa que, nas canções populares de amor, o cavalo "permanece um símbolo de virilidade" (JAKOBSON, 1973, p. 149).

No entanto, a palavra utilizada no poema é kobylka. Em primeiro lugar, trata-se de um animal de gênero feminino, portanto, uma égua e, em segundo lugar, a presença do sufixo diminutivo - $k a$ indica um cavalo de porte pequeno e/ou velho. O cavalinho velho e imprestável contrasta com o status heroico do bogatyr. Além disso, como no poema há apenas duas personagens femininas, a noiva e a égua, cria-se um paralelo essencial entre elas, que ganha ainda mais força nas linhas finais, principalmente quando lemos: "Quem fez mal monta o corcel" (o que em russo equivale a "O inimigo montou a égua"). Essa conotação sexual está presente, ainda que de modo muito sútil, no texto puchkiniano.

Por outro lado, se considerarmos tradução como um processo de criação de novos sentidos (LOTMAN, 2001, p. 565-566; ARROJO, 2007, p. 23-24), notaremos que no texto em português surge um paralelo entre o "cavaleiro" e o "corcel." Esse par "cavaleiro-corcel", arquetípico do folclore, aproxima a tradução brasileira das baladas escocesas. Nesse sentido, a 
derrota do cavaleiro é espelhada na imagem do corcel montado pelo assassino.

Há também uma ambiguidade curiosa e certamente proposital no desfecho puchkiniano. Na versão em português, os versos finais são:

E eis que a noiva aguarda o noivo, Não o morto, mas o novo.

Ou seja, a noiva espera não o cavaleiro morto, mas o novo, provavelmente, aquele que o seu vencedor e assassino. Já em russo, se recorrermos à tradução literal, seria:

Já a dona de casa espera o amado

Não assassinado, mas vivo.

À primeira vista, parece que se trata de uma donzela fiel à espera do amado, e começamos a desconfiar que ela é cúmplice do assassinato apenas ao voltar e reler as linhas:

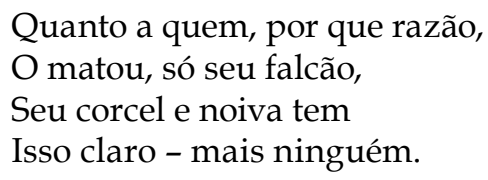

O desfecho "confuso" transforma o leitor em uma espécie de detetive, obrigando-o a investigar o poema linha por linha em busca das respostas: por que o herói estava montado em um cavalo imprestável, para ser um alvo mais fácil? Como ele foi derrotado ou assassinado, será que houve de fato uma batalha ou o bogatyr foi pego de surpresa? Por que a sua noiva (esposa, no texto russo), que estava em casa, mesmo assim sabia quem o havia matado e por que razão? No texto em russo, Púchkin usa o adjetivo "jovem" ao se referir a ela: seria para destacar que o bogatyr não era? É uma espécie de protonovela policial em versos. Além disso, o desfecho ambíguo remete a ambas as baladas escocesas que originaram o poema puchkiniano. A "brincadeira" que o poeta trava com o leitor é algo muito típico da literatura erudita moderna, o que afasta Os corvos da sua origem folclórica.

A trajetória das traduções de Púchkin no Brasil demonstra um fenômeno importante: os autores e/ou textos 
considerados fundadores dentro da cultura de origem não necessariamente preservam esse status ao serem transferidos/ traduzidos para outra cultura.

No caso particular do poema Os corvos, a abordagem de todos os quatro textos como um conjunto revela várias curiosidades: primeiramente, as baladas foram anotadas (e, muito provavelmente, com algumas alterações) por Walter Scott, depois "transcriadas" no poema de Púchkin, que, por sua vez, foi vertida para o português. Nesse processo, cada uma das versões foi influenciada pelo contexto da sua criação: no caso das baladas, nota-se, é claro, uma forte presença dos elementos mitológicos, que, no poema puchkiniano, são interpretados a partir do folclore russo e eslavo (salgueiro, bogatyr), porém sofrem alterações importantes (a quebra da expectativa do leitor). Na versão brasileira, os tradutores reforçaram as origens folclóricas do poema e, mais precisamente, a sua acedência às baladas escocesas. Por fim, respondendo a questão levantada por Púchkin a respeito da poesia russa ser traduzível ou não, a experiência empreendida por Boris Schnaiderman e Nelson Ascher mostra que a sua intraduzibilidade (JAKOBSON, 1973; LOTMAN, 2001) resulta em um processo essencialmente criativo.

\section{REFERÊNCIAS}

AGAMBEN, Giorgio. Estâncias - a palavra e a fantasma na cultura ocidental. Tradução de Selvino José Assmann. Belo Horizonte: Editora UFMG, 2007.

ARROJO, Rosemary. Oficina de tradução: a teoria na prática. São Paulo: Ática, 2007.

BOTTMANN, Denise. Púchkin no Brasil, I. (9 de nov. de 2012). Disponível em: <http://naogostodeplagio.blogspot.com.br/ search?q=púchkin $\geq$ Acesso em 04/07/2016. . Traduções de Aleksandr Púchkin no Brasil. Belas

Infiéis, v. 3, n. 1, p. 241-247, 2014.

GASPÁROV, Mikhail. Semantítcheski oreol púchkinskogo tchetyriokhstópnogo khoréia (A auréola semântica do troqueu de quatro pês de Púchkin). 1990. Disponível em: <http://www. ruthenia.ru/document/526619.html\# $\left(^{*}\right)>$ Acesso em:17/02/2017. 
GOMIDE, Bruno. Da estepe à caatinga: O romance russo no Brasil (1887-1936). Tese de doutorado, Unicamp, 2004.

INGARDEN, Roman. A obra de arte literária. Tradução de Albin

E. Beau, Maria da Conceição Puga e João F. Barrento. Lisboa: Calouste Gulbenkian, 1965.

FERREIRA, Jerusa Pires. Matrizes impressas do oral. Conto russo no serão. São Paulo: Ateliê Editorial, 2014.

JAKOBSON, Roman. Linguística e comunicação. Tradução de Izidoro Blikstein e José Paulo Paes. São Paulo: Cultrix, 1973.

LOTMAN, Iúri. Kultúra kak kollektívnyi intellekt i probliémy iskússtvennogo rázuma. (A cultura como inteligência coletiva e os problemas da inteligência artificial). In: Semiosfera. São Petersburgo: Iskússtvo-SPB, 2001, p. 557-567.

MELETÍNSKI, Eleazar. Vóron (Corvo). In: Mify naródov mira. Entsiklopiédia. (Mitos dos povos do mundo. Enciclopédia). Moscou: Soviétskaia entsiklopiédia, 1980, v. 1, p. 245-247.

PROPP, Vladímir. Morfologia do conto maravilhoso. Tradução de Jasna Paravich Sarhan. Rio de Janeiro: Forense-Universitária, 1984.

PÚCHKIN, Aleksandr. A dama de espadas. Prosa e poemas. Tradução de Boris Schnaiderman e Nelson Ascher. São Paulo: Editora 34, 2013.

. Noites egípcias e outros contos. Tradução de Cecília Rosas. São Paulo: Hedra, 2010.

PUSHKIN, Alexander. Contos de Belkin. Tradução de Klara Gourianova. São Paulo: Nova Alexandria, 2003.

TOMACHÉVSKI, Borís. Primetchánia (Notas). In: Púchkin, A. S. Obra completa em 10 volumes. Volume 3. Leningrado: Naúka, 1977, p. 433-476.

TOPOROV, Vladímir. Mirovóie drevo (A árvore do mundo). In: Mify naródov mira. Entsiklopiédia. (Mitos dos povos do mundo. Enciclopédia). Moscou: Soviétskaia entsiklopiédia, 1980, volume 1, p. 398-406.

SCOTT, Walter. The Minestrelsy of the Scottish Border. 1801-1803. Disponível em: <https://ebooks.adelaide.edu.au/s/scott/ walter/minstrelsy-of-the-scottish-border/index.html $>$. Acesso em: 20/04/2016. 
SCHNAIDERMAN, Boris. "Púchkin e Gonzaga". Da sanfoninha ao violão. Caderno de Literatura e Cultura Russa I. São Paulo, 2004, p. 69-75.

A aventura dos títulos. In: Tradução, ato desmedido. São Paulo: Perspectiva, 2015, p. 34-37.

VOGUE, Melchior de. O romance russo. Rio de Janeiro: Editora A noite, 1950.

ZUMTHOR, Paul. Introdução à poesia oral. Tradução de Jerusa Pires Ferreira; Maria Lúcia Diniz Pochat; Maria Inês de Almeida. São Paulo: Hucitec, 1997.

\begin{abstract}
Pushkin's The crows: the translation of a translation

The history of Alexander Pushkin's translations in Brazil, as well as the history of the Pushkin studies, evidences gaps in these areas, especially with regard to his poetic heritage. Then, I turn to the particular case of Pushkin's poem The Crows (1828), a free translation of the Scottish ballads The Three Ravens and The twa Corbies, published by Walter Scott in 1802-1803. The semantic analysis of the poem demonstrates significant transformations in relation to the original ballads. In turn, awareness of the folkloric origin of the Pushkin's poem predestined many of the choices made by Brazilian translators, Boris Schnaiderman and Nelson Ascher.
\end{abstract}

Keywords: Alexander Pushkin; Russian poetry; Translation; Semiotics of culture. 